Research Paper:

\title{
Stakeholders' Perceptions of Challenges in the Public Health Nursing Practicum: A Qualitative Study
}

\author{
Reza Negarandeh $^{1}$ (D, Shahzad Pashaeypoor ${ }^{2}$, Dimitrios Theofanidis ${ }^{3}$, Heshmatolah Heydari ${ }^{4,5^{*}}$ (iD)
}

1. Nursing \& Midwifery Care Research Center, School of Nursing and Midwifery, Tehran University of Medical Sciences, Tehran, Iran. 2. Department of Community Health Nursing, School of Nursing and Midwifery, Tehran University of Medical Sciences, Tehran, Iran. 3. Department of Nursing, School for Health, Alexander Technological Educational Institute (ATEITH) of Thessaloniki, Thessaloniki, Greece. 4. Social Determinants of Health Research Center, School of Nursing and Midwifery, Lorestan University of Medical Sciences, Khorramabad, Iran 5. French Institute of Research and High Education (IFRES-INT), Paris, France.

\begin{tabular}{|l|l|}
\hline $\begin{array}{c}\text { use yur device to scan } \\
\text { and read the article online }\end{array}$ & $\begin{array}{l}\text { Cttation: Negarandeh, R., et al. 2021. Stakeholders' Perceptions of Challenges in the Public Health Nursing Practicum: } \\
\text { A Qualitative Study. Journal of Client-Centered Nursing Care, 7(4), pp. 285-294. https://doi.org/10.32598/JCCNC.7.4.385.1 }\end{array}$ \\
dol https://doi.org/10.32598/JCCNC.7.4.385.1
\end{tabular}

(c) (i) (5)

Article info:

Received: 15 Aug 2021

Accepted: 15 Sep 2021

Published: 01 Nov 2021

Keywords:

Community health planning, Nursing students, Public health, Nursing program evaluation, Qualitative research

\section{A B S T RA C T}

Background: Community health nurses have an important role to play in promoting public health. This study attempted to explore the stakeholders' perceptions of challenges in the public health nursing practicum in Iran.

Methods: This qualitative study was carried out in some schools of nursing and health centers in Iran from October 2015 to September 2017. Twenty-three participants, including faculty members of public health nursing, nursing students, home nurses, experts in health centers, and nursing education policymakers were selected by purposeful sampling. Data were collected using individual interviews and were analyzed by Lundman and Graneheim's method of content analysis.

Results: Three themes resulted from the data analysis, including organizational challenges (with sub-categories of "inappropriate implementation of the curriculum due to lack of authority", "the treatment-centeredness of health care system", and "limited fields for nursing practicum"), educational challenges (with sub-categories of "shortcomings of educational curricula" and "the duration and time of practicums"), and workforce challenges (with sub-categories of "the financial burden of public health nursing practicum", "lack of job position for public health nurses", and "factors related to the role of instructors").

Conclusion: Senior managers, community health center administrators, and educational planners can use the challenges and barriers raised in this study to make more appropriate planning for the training of nursing students in public health nursing practicum.

\section{* Corresponding Author:}

Heshmatolah Heydari, PhD.

Address: Social Determinants of Health Research Center, School of Nursing and Midwifery, Lorestan University of Medical Sciences, Khorramabad, Iran Tel: +98 (66) 33120140

E-mail:h-hidari@razi.tums.ac.ir 


\section{Highlights}

- Community health nurses have an important role to play in promoting public health.

- Public health nursing aims to promote and protect the health of people based on nursing knowledge, public health measures, and social sciences.

- It is necessary to assess and evaluate practical nursing education programs from the perspective of those involved.

- The participants of this study summarized the barriers to student nurses' education in public health practicum as organizational, educational, and workforce challenges.

\section{Plain Language Summary}

Community health nurses are known as key members of the health care team who can deliver health care services to clients in three levels of prevention in the community. Practical training is a vital dimension of nursing education, and community health nursing students should be competent for providing health care in the community. The findings of this study revealed that Iranian nursing students face numerous organizational, educational, and workforce challenges in their public health practicum.

\section{Introduction}

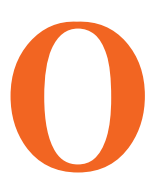

ne of the most important strategies of the World Health Organization (WHO) is to achieve health for all and to benefit from public health nurses all around the world (WHO 2010a). Public health nursing is a combination of nursing and public health that was introduced by Lillian Wald in 1893 (Adeleye \& Ofili 2010) and since then, it aimed at promoting and protecting the health of people based on nursing knowledge, public health measures, and social sciences (Stanhope \& Lancaster 2015). In practice, the main activities of public health nurses include recognizing social capital, assessing health status and identifying health threats, designing and implementing comprehensive care and interventions, and developing public health guidelines in line with state and national policies (WHO 2010b).

In this regard, nurses should acquire public health competencies and skills during their education. Practical experience has a major role in the development of these skills (Heravi et al. 2011). The practicum should lead students to personal and professional development, improvement of self-esteem, and development of interpersonal skills, such as communication, leadership, and intercultural competence (Conway, Amel \& Gerwien 2009; Howard 2014). The practicum should also be used to enrich theoretical knowledge gained in the classroom (León-Montoya, Albar \& León-Larios 2018), and ultimately, help students to obtain the necessary competen- cies that enable the maintenance and promotion of public health and disease prevention (Stanhope \& Lancaster 2015). However, it has been observed that students are marginalized during public health practicum (LeónMontoya, Albar \& León-Larios 2018), which may lead to their reluctance to enter the community as public health nurses (Duah 2015). It has also been observed in various studies that nursing education still focuses on preparing nurses for work in acute care areas, such as hospitals (Duah 2015; Keller, Strohschein \& Schaffer 2011). Yet, the WHO has emphasized the need to empower public health nurses (WHO 2010a).

Iran, like the rest of the world, has been experiencing an increase in urbanization, changing population, growing elderly population, changing lifestyles, and shifting mortalities from infectious diseases to chronic diseases, accidents, and cancers (WHO 2014; Khosravi Shadmani et al. 2019). These changes necessitate the adoption of a medico-sociological focus by Iran's health system.

Nursing was officially started in Iran in 1915 and in 1958 , modules related to social and behavioral sciences were included in the nursing curriculum in accordance with the standards of the International Council of Nurses (ICN) and the WHO. In 1986, five theoretical credits and four clinical credits of public health nursing, as well as two theoretical credits related to the principles of epidemiology, were devoted to the Bachelor's degrees in nursing (Shahshahani et al. 2010). In recent years, nursing curriculum and modules have undergone a transition 
from patient-centered practice to family and society-centered practice (WHO 2010b). However, training of public health nurses in Iran, as in other parts of the world, has had drawbacks as students do not always acquire the necessary skills to enter the public health nursing work environment during their education. Furthermore, during their education practicum, they neither gain positive attitudes towards community development nor acquire the necessary skills to provide services outside the acute centers (Heravi et al. 2011; Karimi Moonaghi et al. 2013; Saberian 2009; Khorasani \& Jowzi 2010).

Delivery of community-based care requires that students have the necessary knowledge, attitude, and skills to provide health services at various levels of prevention. Exploring the perceptions of those engaged in this field can provide valuable information about the status of the practicum training of community health nursing students. Accordingly, this study was conducted with the aim of exploring the stakeholders' perceptions of the challenges in the public health nursing practicum in Iranian society.

\section{Materials and Methods}

This qualitative study with a content analysis approach was conducted from October 2015 to September 2017 in Tehran, Iran. The participants were selected via purposeful sampling. The criteria for entering the study included willingness for participation and engagement in the educational, policymaking, or care-providing activities in the field of public health nursing.

Accordingly, faculty members of public health nursing educational groups, BSc, MSc, and Ph.D. nursing students, public health nurses, physicians, experts of health centers, and nursing education policymakers in Iran were invited to participate in this study.

Data were collected using in-depth, semi-structured interviews. Nineteen face-to-face interviews and four telephone interviews were performed to collect the data. Telephone interviews were conducted due to a lack of access to some participants. An attempt was made to select the participants who had the maximum variation in terms of knowledge, role, experience, age, sex, and place of employment. After explaining the objectives of the study, the time and place of the interviews were determined according to the participants' preferences. The following questions were asked in the interviews: How do you see the clinical training of public health nursing at the bachelor's degree level? What are the threats and opportunities of clinical training in public health nursing?
Is this training method effective? The researcher kept guiding the interview process using probing questions to achieve the research goals. Thus, sampling and data collection continued until data saturation was reached (Speziale, Streubert \& Carpenter 2011). The duration of each interview was 20 to 40 minutes. All interviews were conducted and recorded by one of the researchers.

Data analysis was performed simultaneously with the interviews based on the proposed method by Lundman and Graneheim (Graneheim \& Lundman, 2004). Thus, the interviews were immediately transcribed verbatim and were read repeatedly to extract primary codes. Subsequently, similar primary codes were merged and bigger categories were formed based on their similarities and differences, and eventually, hidden concepts were extracted from the data.

In order to show trustworthiness, Lincoln and Guba's criteria of credibility, transferability, dependability, and confirmability were used (Schwandt Lincoln \& Guba 2007). For this purpose, in terms of credibility, the main researcher maintained long-term engagement with the participants that helped to gain their trust and create rich data. Member checks were used after the formation of categories. If categories and subcategories conflicted with their views, they were readjusted and modified. In terms of transferability, we tried to present the context of the study and the participants' views with comprehensive detail. To maintain dependability, two faculty members who were also experts in qualitative research reviewed and examined the research process and the data analysis to ensure that the findings are consistent and could be repeated. To establish confirmability, an independent reviewer verified the research process and interpretations of the data.

\section{Results}

In this study, 19 face-to-face interviews and four telephone interviews were performed (Table 1). Three themes were obtained from the data analysis: organizational challenges (with sub-categories of "inappropriate implementation of the curriculum due to lack of authority", "the treatment-centeredness of health care system", and "limited fields for nursing practicum"), educational challenges (with sub-categories of "shortcomings of educational curricula", and "the duration and time of practicums"), and workforce challenges (with sub-categories of "the financial burden of public health nursing practicum", "lack of job position for public health nurses", and "factors related to the role of instructors") (Table 2). 
Table 1. Demographic characteristics of the participants

\begin{tabular}{|c|c|c|c|c|}
\hline Sex & Age (Year) & Position & Work Experience (Year) & Level of Education \\
\hline Female & 23 & Nursing student & - & Undergraduate nursing student \\
\hline Female & 22 & Nursing student & - & Undergraduate nursing student \\
\hline Female & 24 & Nursing student & - & Undergraduate nursing student \\
\hline Male & 58 & Faculty member- group manager & 28 & PhD Student in Nursing \\
\hline Male & 27 & Nursing student & - & Undergraduate nursing student \\
\hline Female & 31 & Nursing student & - & $\begin{array}{l}\text { Postgraduate nursing student in } \\
\text { community health nursing }\end{array}$ \\
\hline Male & 32 & Nursing student & - & $\begin{array}{l}\text { Postgraduate nursing student in } \\
\text { community health nursing }\end{array}$ \\
\hline Male & 24 & Nursing student & - & Undergraduate nursing student \\
\hline Female & 52 & Faculty member & 27 & Ph.D. in Nursing \\
\hline Female & 43 & Faculty member & 8 & Ph.D. in Nursing \\
\hline Male & 49 & Faculty member & 23 & Ph.D. in Nursing \\
\hline Female & 44 & Faculty member- educational deputy & 10 & PhD in Nursing \\
\hline Female & 36 & Employee in health center & 13 & Bachelor of Science in Midwifery \\
\hline Male & 38 & Employee in health center & 16 & Bachelor of Science in Public health \\
\hline Female & 53 & Faculty member- group manager & 25 & Master of Science in nursing \\
\hline Female & 56 & Faculty member & 30 & Ph.D. in health promotion \\
\hline Male & 42 & Faculty member & 16 & Ph.D. Student in Nursing \\
\hline Female & 48 & Faculty member & 26 & Master of Science in nursing \\
\hline Female & 44 & Faculty member- group manager & 12 & Ph.D. in Nursing \\
\hline Male & 49 & Faculty member & 24 & Ph.D. in health promotion \\
\hline Male & 49 & Faculty member & 27 & $\begin{array}{c}\text { Master of Science in Health Promo- } \\
\text { tion }\end{array}$ \\
\hline Male & 56 & Faculty member- group manager & 26 & Ph.D. in Nursing \\
\hline Male & 41 & Home care nurse & 18 & Bachelor of Science in nursing \\
\hline
\end{tabular}

Client- Centered Nursing Care

\section{Organizational challenges}

Organizational structure determines the roles, power, authority, and responsibilities and shows how information is transferred between different levels of the organization. Analysis of the data showed that organizational problems negatively affected the education of community health nursing students. Lack of community-based nursing staff and their lack of participation in the planning and management of community-based services reduces the power and authority of public health nursing educators for community-based educational activities. People's tendency to direct referral to specialists in clinics and hospitals, as well as the lack of comprehensive care services in the community can have a negative impact on the education of community health nursing students. This theme included three sub-categories: "inappropriate implementation of the curriculum due to lack of au- 
Table 2. The themes and categories of challenges in the public health nursing practicum

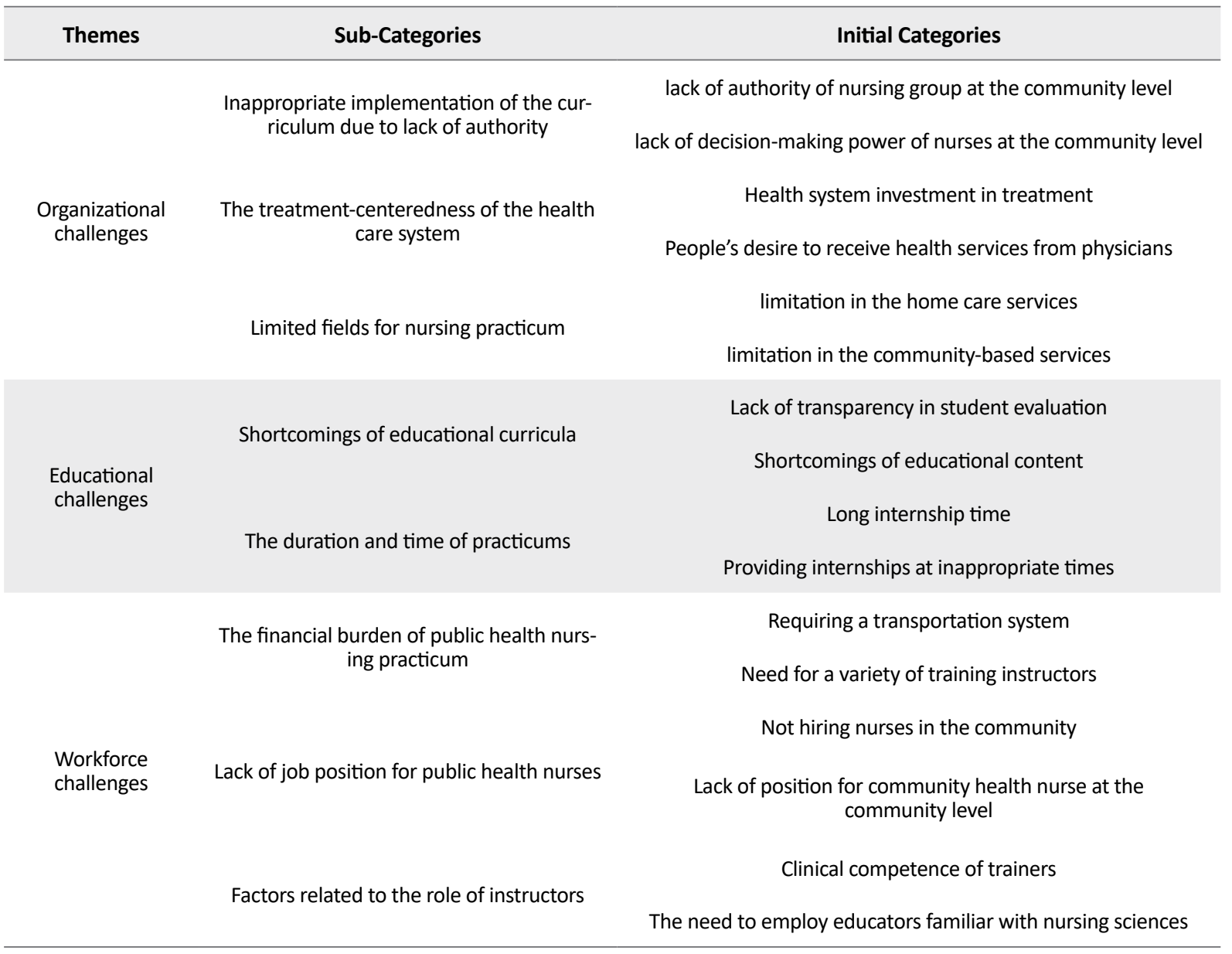

Client- Centered Nursing Care

thority", "the treatment-centeredness of health care system", and "limited fields of clinical education".

Inappropriate implementation of the curriculum due to lack of authority

Participants pointed to the lack of authority and decision-making power of nurses at the community-based health centers. They attributed this to the lack of nurses' command position in such centers, which also causes remarkable sub-ordinance of nurses. Furthermore, officials or experts working at these centers often see students as intrusive people or even outsiders, and instructors cannot teach anything to students without coordinating first with the relevant center. In this regard, one of the faculty members of the community health nursing group stated: ".... In public health nursing, we do not have the necessary authority. This means that I cannot make plans and be in charge of a health center completely..." (p4).
The treatment-centeredness of the health care system

The participants believed that the health care system of Iran is a treatment-oriented health system, in which disease and physician are the dominant components. Also, people are more interested in receiving health services offered in hospitals by physicians rather than non-physician experts. Participants in this study believed that the Iranian health care system intervenes once the disease is established and has limited programs in prevention and health promotion for people in the community. Consequently, students are mainly trained and exposed to only clinical environments. With regard to the desire of nurses to work in hospitals, one of the faculty members of the community health nursing group stated: “...The health system has moved to do more treatment than prevention..." (p4).

\section{Limited fields for nursing practicum}

One of the factors highlighted by the participants was the limited fields for public health nursing practicums. 
There are home health care and community-based services in Iran, but nursing students have not full access to these services. The participants stated that there is a need for diverse improvements in the public health nursing practicum training so that students can develop a holistic view and be able to deliver public health services in the community after graduation. Moreover, data analysis showed that the nursing students often have to work mainly with child growth monitoring and vaccination, and this is the closest clinical contact within the community environment. The participants pointed to a range of areas and fields for the empowerment of public health nurses and stated that any place outside treatment centers in which clients can receive health services can be considered as an educational field. One of the participants stated: "...Students should go to different places like mosques, schools, and homes for real training..." (p12).

\section{Educational challenges}

Analysis of data showed that one of the challenges of community health nursing practicum training is the shortcomings in the curriculum related to these courses so that the goals, content, and relevant educational processes are not considered properly. In this theme, there were two sub-categories, including "shortcomings of educational curricula" and "the duration and time of practicums".

\section{Shortcomings of educational curricula}

The educational programs need to have a comprehensive, systematic, and proper roadmap in order to achieve their goals. Data analysis shows that despite the prevalence of chronic diseases, the educational curriculum of public health nursing does not focus on the care of chronic patients at the community level. The interviewees also highlighted the lack of effective educational strategies, defects in the process of student evaluation, and lack of transparency between health sciences and nursing services at the community level. In this regard, one of the participants stated: "... The content is not in line with the goal of community health nursing; this means that if we explain community-based nursing services to students, the headings will not show this!!! The topics focus more on health lessons !!...” (p4).

\section{The duration and time of practicums}

The length of practicum was also one of the problems that the participants emphasized during this study. They indicated that the duration of the practicum is far longer than it needed to be in order to achieve its objectives.
This was also considered to cause boredom and disinterest so that students have to do simple repetitive and routine works for a long time. Participants in this study also pointed out that in some cases, a practicum has been scheduled in a way that begins before the students have studied the related theoretical modules and acquired the necessary knowledge. One of the students stated: “.... I think the work here has become a routine. We have been coming here for a month now and we are doing only repetitive work ..." (p1).

\section{Workforce challenges}

Data analysis showed that labor-related factors can affect students' learning. The presence of experienced staff in the field, accessibility of internship settings, and the use of instructors with appropriate knowledge and skills can affect students' clinical education. In this theme, there were three sub-categories, including "the financial burden of public health nursing practicum", "lack of work position for public health nurses", and "factors related to the role of instructors".

\section{The financial burden of public health nursing practicums}

Data analysis showed that public health practicum is costlier compared to undergraduate clinical nursing education programs. The participants in this study pointed out that if the public health nursing practicum is conducted, it requires a suitable transportation schedule that should be designated for students throughout the entire duration of the practicum. On the other hand, due to the wide variety of fields that should be covered by the public health nursing practicum, such as environmental and vocational health, the experts of each of these fields should also be involved with the training. Yet, this would not be possible unless each of them is paid an adequate teaching fee.

However, the participants pointed out that these people may have no experience in teaching; therefore, holding continuing education courses with the above-mentioned purpose in mind would be necessary for them; but these would also be costly. In this regard, one of the participants who were in charge of overseeing the program and cost of public health nursing practicum as a deputy director of education in a nursing school stated: “... Last year, our practicum program in public health nursing which took place in health centers with the aim of visiting homes was very costly..." (p12). 


\section{Lack of job position for public health nurses}

Job position refers to the professional area where each person could serve after acquiring the necessary qualifications. Data analysis indicated that one of the important challenges of public health nursing education is the lack of proper job positions for public health nurses after graduation. Also, in the health care system of Iran, there are not many places for public health nurses to provide related services to the community and most nursing graduates end up being employed in hospitals, and this leads to confusion among nursing students during the training process. One of the nursing instructors stated: “...In practice, you will not find a place for public health nurses to be shown to students, so they will not be able to see their future activities and see if their services are important.... " (p9). The participants also believed that because the job position of community health nurses is not defined in Iran, the skill and education requirements of community health nursing students are unclear.

\section{Factors related to the role of instructors}

Data analysis showed that factors related to the instructors responsible for teaching students can affect the quality of nursing education in public health nursing. The participants emphasized the lack of competent clinical instructors, pointing out that public health nursing requires teachers who, in addition to having theoretical knowledge, have extensive experience in practical aspects of public health nursing. They stated that most of the practicum is delivered by instructors who have little experience in public health nursing and are not competent in all aspects of this field. They also believed that other experts working in community health centers should be used as instructors and have a role in finetuning and managing programs and courses; also local experts in health centers should have a more inclusive role in student training. One of the participants stated: “... Among faculty members, one should be active in the field of community health nursing, one in the field of chronic diseases ..." (p9).

\section{Discussion}

The findings of this study showed that public health nursing education has a variety of problems, including organizational, educational, and workforce challenges. In line with the major findings of this study regarding the status of community health nursing in Iran, these problems were also observed in the study by Heydari et al. (Heydari, Rahnavard \& Ghaffari 2017).
This finding is in line with the results of other studies, which have highlighted the importance of practicum fields that create motivation and clinical competence in students (León-Montoya, Albar, \& León-Larios 2018; Ildarabadi et al. 2013). In this regard, evidence suggests that practicum in emergency and ICU settings is perceived as more interesting and exciting by students as they like to learn different and exciting techniques, whereas taking care of chronic and elderly patients at home is viewed as boring for them (van Iersel et al. 2016). Yet, the use of new and non-traditional practicum fields, such as charity centers for the protection of the poor, shelters, workplaces, prisons, shopping malls, police stations, mosques, churches, and schools in the practical training of public health nurses can motivate students (Cohen \& Gregory 2009; Pijl-Zieber \& Grant Kalischuk, 2011) and improve their knowledge and skills.

Public health nurses are identified as the key components of any given healthcare team that should be able to be active at different levels of prevention (Organization 2017), and as role models who are important elements in nursing education (Mokhtari Nouri et al. 2014). In the practicum fields, students often compare themselves with role models (Phuma-Ngaiyaye Bvumbwe \& Chipeta 2017) and this creates a sense of replication and imitation in them, which may ultimately lead to effective learning according to Bandura's social learning model (Beth Perry 2009). Therefore, in order to promote practical training in public health nursing, public health nurses should be involved at different levels of prevention so that nursing students can see these role models and by observing and emulating them, such roles can be formed in them.

The participants emphasized the shortcomings of the public health nursing curriculum. Although the undergraduate nursing curriculum in Iran includes community health nursing courses, these do not fit with the goals of community-based nursing (Asadi-Lari et al. 2004). This is while the WHO emphasizes that undergraduate nursing students need to be trained to identify and plan for at-risk populations, and then to implement and evaluate these programs. (Organization 2010a). Considering the demographic changes that have taken place in Iran and the course of various diseases, enrichment of public health nursing is necessary in order to provide effective community-based services.

The duration of practicum was also one of the problems that the participants underlined in this study. In this regard, studies have shown that the duration and time of a practicum should be defined so that the students acquire 
the skills and experience necessary to provide health services. In this regard, the findings of a study showed that students should spend 360 hours on practicum during education, as well as 240 hours on residency; hence, the students are obliged to spend 600 hours on the practicum (Swider et al. 2006). However, the curriculum of undergraduate nursing students in Iran has defined 240 hours of public health nursing education, which seems to be adequate according to the aforementioned statements. Therefore, it seems that students' complaints and dissatisfaction are more likely to be associated with the repetitive nature of the practicum and inefficiency in its quality management. Thus, by diversifying the fields of practicum and developing appropriate programs to manage them, the quality and effectiveness of practicum in public health nursing could be improved. Data analysis indicated that conducting public health nursing practicum is costly in comparison with other undergraduate nursing practicums. Consistent with the findings of this study, another study reported that practice at the local or rural level is inherently costly given the type of students and services provided. (Hudson, Westib \& Farmer 2012). However, another study found that the presence of students in community-based areas could be cost-effective (Cristobal \& Worley 2012), because the use of preceptorship in educating public health nursing students can have many benefits for students, society, preceptors, faculties, universities, and centers that provide such services (Nightengale 2019). So far, no study has been carried out on the cost assessment and its effectiveness of public health nursing practicum in order to scientifically analyze the cost-benefit and total cost of public health nursing practicum (Bowles et al. 2014). Further studies are needed to better manage resources and to improve the quality of nursing education in public health nursing.

Factors related to the instructors of public health nursing were one of the obstacles identified in this study. In line with the findings of this study, evidence suggests that it is difficult to find public health nursing instructors who have the required competence and can guide students in the clinical field (Fawaz, Hamdan-Mansour \& Tassi 2018). In this regard, clinical instructors should, in addition to being competent and proficient in theoretical and practical lessons, have adequate experience in the field of practicum and supervision of students. According to other studies, the use of healthcare professionals' full capacity can be effective in the teaching of public health nursing students in comprehensive health centers (Baglin \& Rugg 2010). On the other hand, a variety of services are provided to clients in the comprehensive health center; therefore, an instructor may not possess all related skills. It is therefore appropriate to use the capacity of additional related healthcare professionals (Adeleye \& Ofili 2010). According to this finding, the use of the mentorship approach can be effective in the teaching of public health nursing students (Fereidouni et al. 2017).

\section{Conclusion}

Nursing students cannot acquire the necessary competencies to provide community-based services due to the challenges of practical training in public health nursing. Therefore, eliminating the structural and processual problems along with proper management of such training courses is inevitable in the training of competent nurses capable of providing high-quality communitybased nursing services. Also, education authorities and policymakers in the Iranian health care system should redefine the position of public health nursing services and design appropriate models for practical training of public health nursing at the undergraduate level.

\section{Ethical Considerations}

\section{Compliance with ethical guidelines}

This study was approved by the Ethics Committee of Tehran University of Medical Sciences (IR.TUMS. REC.1394.1002). The purpose of the study was explained to all the participants and they were assured of anonymity and confidentiality of their information. Permission to record interviews was also obtained from all the participants. They had the right to leave the study whenever they wished without any repercussions. Written informed consent was obtained from all participants.

\section{Funding}

This study was funded by the Tehran University of Medical Sciences, Iran (94-02-99-29078).

\section{Authors' contributions}

Conceptualization and supervision, methodology: Reza Negarandeh, Heshmatolah Heydari, Shahzad Pashaeypoor; Investigation, writing- original draft, and writing review \& editing: Reza Negarandeh, Heshmatolah Heydari, Shahzad Pashaeypoor, Dimitrios Theofanidis; Data collection: Heshmatolah Heydari, Shahzad Pashaeypoor; Data analysis: Reza Negarandeh, Heshmatolah Heydari, Shahzad Pashaeypoor, Dimitrios Theofanidis.

\section{Conflict of interest}

The authors declared no conflict of interest. 


\section{References}

Adeleye, O. A. \& Ofili, A. N., 2010. Strengthening intersectoral collaboration for primary health care in developing countries: Can the health sector play broader roles? Journal of Environmental and Public Health, 2010, p. 272896. [DOI:10.1155/2010/272896] [PMID] [PMCID]

Asadi-Lari, M., et al. 2004. Public health improvement in Iranlessons from the last 20 years. Public Health, 118(6), pp. 395-402. [DOI:10.1016/j.puhe.2004.05.011] [PMID]

Baglin, M. \& Rugg, S., 2010. Student nurses' experiences of community-based practice placement learning: A qualitative exploration. Nurse Education in Practice, 10(3), pp. 144-52. [DOI:10.1016/j. nepr.2009.05.008] [PMID]

Beth Perry, R. N., 2009. Role modeling excellence in clinical nursing practice. Nurse Education in Practice, 9(1), pp.36-44. [DOI:10.1016/j. nepr.2008.05.001] [PMID]

Bowles, K. A., et al. 2014. The costs and benefits of providing undergraduate student clinical placements for a health service organisation: A rapid review. Health Education and Training Institute [Internet]. Cited 6 November 2021, https:/ / researchmgt.monash edu/ws/portalfiles/portal/38827515/35430376.pdf

Cohen, B. E. \& Gregory, D., 2009. Community health clinical education in Canada: Part 2-developing competencies to address social justice, equity, and the social determinants of health. International Journal of Nursing Education Scholarship, 6(1). [DOI:10.2202/1548923X.1638]

Conway, J. M., Amel, E. L. \& Gerwien, A. D. P., 2009. Teaching and learning in the social context: A meta-analysis of service learning's effects on academic, personal, social, and citizenship outcomes. Teaching of Psychology, 36(4), pp. 233-45. [DOI:10.1080/00986280903172969]

Cristobal, F. \& Worley, P., 2012. Can medical education in poor rural areas be cost-effective and sustainable: The case of the Ateneo de Zamboanga University School of Medicine. Rural Remote Health, 12, p. 1835. [DOI:10.22605/RRH1835] [PMID]

Duah, M. A., 2015. Baccalaureate nursing students' perceptions of community health nursing as a career [MSc. thesis]. Ottawa: University of Ottawa. [DOI:10.1016/j.ijans.2018.10.005]

Fawaz, M. A., Hamdan-Mansour, A. M. \& Tassi, A., 2018. Challenges facing nursing education in the advanced healthcare environment. International Journal of Africa Nursing Sciences, 9, pp. 105-10. [DOI:10.1016/j.ijans.2018.10.005]

Fereidouni, Z., et al. 2017. Attitudes toward Community-based training and internship of nursing students and professors: A qualitative study. Investigación y educación en enfermeria, 35(2), pp. 243-51. [DOI:10.17533/udea.iee.v35n2a13] [PMID]

Graneheim, U. H. \& Lundman, B., 2004. Qualitative content analysis in nursing research: Concepts, procedures and measures to achieve trustworthiness. Nurse Education Today, 24(2), pp. 105-12. [DOI:10.1016/j.nedt.2003.10.001] [PMID]

Heravi, M., et al. 2011. Nursing Students' comprehension of community health nursing training in field: A qualitative research. Iranian Journal of Medical Education, 11(5), pp. 526-38. http://ijme.mui.ac.ir/article-1-1075-fa.html
Heydari, H., Rahnavard, Z. \& Ghaffari, F., 2017. Exploring the position of community-based nursing in Iran: A qualitative study. International Journal of Community Based Nursing and Midwifery, 5(4), pp. 386-96. [PMID] [PMCID]

Howard, J. 2014. Service-learning research: Foundational issues. In: S. H Billig. \& A. S. Waterman (eds), Studying Service-Learning. New York: Routledge. https://www google.com/books/edition/Studying_Service_Learning/ gaqPAgAAQBAJ?hl=en\&gbpv=1\&dq

Hudson, J. N., Westib, K. M. \& Farmer, E., 2012. Medical students on long-term regional and rural placements: What is the financial cost to supervisors? Rural and Remote Health, 12(2), p. 1951. [DOI:10.22605/RRH1951] [PMID]

Ildarabadi, E., et al. 2013. The process of community health nursing clinical clerkship: A grounded theory. Iranian Journal of Nursing and Midwifery Research, 18(6), pp. 457-62. [PMID] [PMCID]

Karimi Moonaghi, H., et al. 2013. Challenges of community health nursing education in Iran. International Journal of Community Based Nursing and Midwifery, 1(1), pp. 62-8. https:// ijcbnm.sums.ac.ir/article_40634.html

Keller, L. O., Strohschein, S. \& Schaffer, M. A., 2011. Cornerstones of public health nursing. Public Health Nursing, 28(3) pp. 249-60. [DOI:10.1111/j.1525-1446.2010.00923.x] [PMID]

Khorasani, P. \& Jowzi, M., 2010. Service learning: A method for providing service along with learning in community based education. Iranian Journal of Nursing and Midwifery Research, 11(4). http://ijnmr.mui.ac.ir/index.php/ijnmr/article/ view/105

Khosravi Shadmani, F., et al. 2019. Trend and projection of mortality rate due to non-communicable diseases in Iran: A modeling study. PloS One, 14(2), p. e0211622. [DOI:10.1371/journal. pone.0211622] [PMID] [PMCID]

León-Montoya, G., Albar, M. J. \& León-Larios, F., 2018. Community public health practicum in the Amazon region of Peru: Student experiences. Journal of Prevention $\mathcal{E}$ Intervention in the Community, 46(1), pp. 73-83. [DOI:10.1080/10852352.2018.138 6271] [PMID]

Mokhtari Nouri, J, et al. 2014. Experiences of role model instructors and nursing students about facilitator factors of role-modeling process: A qualitative research. Iranian Journal of Nursing and Midwifery Research, 19(3), pp. 248-54. [PMID] [PMCID]

Nightengale, F., 2019. Public health nursing preceptor handbook [Internet]. Cited 6 November 2019, https://health.mo.gov/ living/lpha/phnursing/preceptor.pdf

Phuma-Ngaiyaye, E., Bvumbwe, T. \& Chipeta, M. C., 2017. Using preceptors to improve nursing students' clinical learning outcomes: A Malawian students' perspective. International Journal of Nursing Sciences, 4(2), pp. 164-8. [DOI:10.1016/j. ijnss.2017.03.001] [PMID] [PMCID]

Pijl-Zieber, E. M. \& Grant Kalischuk, R., 2011. Community health nursing practice education: Preparing the next generation. International Journal of Nursing Education Scholarship, 8(1), pp. 1-13. [DOI:10.2202/1548-923X.2250]

Saberian, M., 2009. The curriculum of nursing BSc course in the viewpoints of the. Journal of Medical Education, 3(2), pp. 65-70. https://sites.kowsarpub.com/jme/articles/105021.html 
Schwandt, T. A., Lincoln, Y. S. \& Guba, E. G., 2007. Judging interpretations: But is it rigorous? Trustworthiness and authenticity in naturalistic evaluation. New Directions for Evaluation, 114(2007), pp. 11-25. [DOI:10.1002/ev.223]

Shahshahani, M. S., et al. 2010. The study of optimal nursing position in health care delivery system in Iran. Iranian Journal of Nursing and Midwifery Research, 15(4), pp. 150-4. [PMID] [PMCID]

Speziale, H. S., Streubert, H. J. \& Carpenter, D. R. 2011. Qualitative research in nursing: Advancing the humanistic imperative. Philadelphia: Lippincott Williams \& Wilkins. https:// www.google.com/books/edition/Qualitative_Research_in_ Nursing/ xNByh3B1Wt0C?hl=en\&gbpv $=1 \& \mathrm{dq}$

Stanhope, M. \& Lancaster, J., 2015. Public health nursing-ebook: Population-centered health care in the community. Amesterdam: Elsevier Health Sciences. https://www.google.com/books/edition/Public_Health_Nursing_E_Book/ mvWQCgAAQBAJ?hl=en

Swider, S., et al. 2006. Matching a graduate curriculum in public/community health nursing to practice competencies: The Rush University experience. Public Health Nursing, 23(2), pp. 190-5. [DOI:10.1111/j.1525-1446.2006.230211.x] [PMID]

van Iersel, M., et al. 2016. Nursing students' perceptions of community care and other areas of nursing practice-A review of the literature. International Journal of Nursing Studies, 61, pp. 1-19. [DOI:10.1016/j.ijnurstu.2016.05.011] [PMID]

World Health Organization (WHO)., 2010a. Framework for action on interprofessional education and collaborative practice [Internet]. Cited 6 November 2021, https://www.who.int/ publications/i/item/framework-for-action-on-interprofessional-education-collaborative-practice

World Health Organization (WHO)., 2010b. A framework for community health nursing education. Cited 6 November 2021, https://apps.who.int/iris/handle/10665/204726

World Health Organization (WHO)., 2014. Noncommunicable diseases country profiles 2018. Cited 6 November 2021, https://apps.who.int/iris/handle/10665/274512

World Health Organization (WHO)., 2017. Enhancing the role of community health nursing for universal health coverage. Cited 6 November 2021, https://apps.who.int/iris/handle/10665/255047 